\title{
Influência da Temperatura na Atividade de Amilase e Protease de Rhizopus oligosporus cultivado por Fermentação em Estado Sólido
}

\author{
Bruna Escaramboni ${ }^{1}$, Douglas Fernandes da Silva ${ }^{1}$, e Pedro de Oliva Neto ${ }^{2}$ \\ ${ }^{1}$ Universidade Estadual Paulista - Departamento de Microbiologia e Bioquímica \\ CEP 13506-900 Rio Claro - São Paulo - E-mail: douglasfsilva@gmail.com \\ ${ }^{2}$ Universidade Estadual Paulista - Departamento de Ciências Biológicas \\ CEP 19.806-900 Assis - São Paulo
}

\begin{abstract}
RESUMO
Amilases e proteases constituem um dos principais grupos de enzimas industriais pelo seu amplo espectro de aplicações biotecnológicas. Elas podem ser obtidas a partir de fontes microbianas e com altos rendimentos por processos de fermentação em estado sólido (FES). Conhecer as características bioquímicas das enzimas é fundamental para adequação aos processos industriais. O objetivo do trabalho foi determinar a melhor temperatura para atividade das enzimas amilase e protease de Rhizopus oligosporus obtidas por fermentação em estado sólido utilizando farelo de trigo como substrato. Os melhores valores para atividade amilolítica $e$ proteolítica foram obtidos nas temperaturas de $55-65^{\circ} \mathrm{C}$ e de $50-60^{\circ} \mathrm{C}$, respectivamente. Estes resultados sugerem que as enzimas estudadas podem ser utilizadas em processos que empregam elevadas temperaturas.
\end{abstract}

Palavras-chave: Amilase; Protease; Rhizopus oligosporus, Fermentação em Estado Sólido.

\section{INTRODUÇÃO}

As amilases compreendem uma importante classe enzimática com numerosas aplicações industriais e biotecnológicas, representando $25 \%$ do mercado de enzimas ${ }^{1}$. No cenário atual há uma gama extensiva de aplicações tais como nas indústrias de alimentos, detergentes, papéis, têxteis, panificação, indústria química e farmacêutica e na fabricação de etanol ${ }^{2,}{ }^{3},{ }^{4}$. As proteases são enzimas que catalisam a clivagem das ligações peptídicas das proteínas. Elas têm ampla aplicação em detergentes, processamento de alimentos e na indústria do couro, bem como um crescente desenvolvimento do seu uso como uma classe de agentes terapêuticos ${ }^{5}$.

A principal vantagem do uso de micro-organismos para a produção de enzimas é o potencial econômico e capacidade de produção em larga escala, além da relativa facilidade de manipulação e obtenção de enzimas com características específicas ${ }^{6,7}$. A fermentação em estado sólido (FES) tem ganhado a atenção das pesquisas nos últimos 20 anos, e credibilidade entre muitas corporações industriais. Tem diversas vantagens sobre o processo convencional de fermentação submersa, muitas delas estão relacionadas à fisiologia especial apresentada pelos fungos em FES ${ }^{8}$.

A maioria das enzimas estudadas podem ser agrupadas sob o mesmo modelo estrutural, apesar de apresentarem características bioquímicas diferentes, como efeito da temperatura, $\mathrm{pH}$, 


\section{Anais do III Simpósio de Bioquímica e Biotecnologia Trabalho Completo apresentado na seção: PÔSTER}

inibidores e outros. Em geral, são diferenciadas em função da sua atividade, termo-estabilidade, e faixas ótimas de pH de atuação, fatores que determinam sua adequação aos processos industriais $^{9}$.

O objetivo deste trabalho foi estudar a caracterização do extrato enzimático produzido em fermentação em estado sólido por Rhizopus oligosporus quanto a melhor temperatura para atividade amilolítica e proteolítica, visando maior conformação com os processos industriais.

\section{MATERIAL E MÉTODOS}

O fungo foi inoculado, na concentração de $10^{6}$ esporos por grama de substrato, sobre o meio de FES, formulado com farelo de trigo como substrato e suplementado com $\left(\mathrm{NH}_{4}\right)_{2} \mathrm{SO}_{4}$, $\mathrm{KH}_{2} \mathrm{PO}_{4}$ e ureia. As culturas foram incubadas à $30^{\circ} \mathrm{C}$ por 120 horas. Após este período as enzimas foram extraídas pela adição de água destilada, seguida de agitação (180 rpm, 30 min, $30^{\circ} \mathrm{C}$ ) e filtração.

A atividade amilolítica foi determinada utilizando uma solução $0,5 \%(\mathrm{~m} / \mathrm{v})$ de amido em tampão acetato $0,05 \mathrm{M}(\mathrm{pH} 5,5)$ como substrato. A reação enzimática foi climatizada para 40 , $50,55,60,65$ e $70^{\circ} \mathrm{C}$. Uma unidade amilolítica foi definida como a quantidade de enzima que libera o equivalente a $1 \mu \mathrm{mol}$ de açúcar redutor por minuto de reação e quantificado pelo método DNS (ácido 3,5-dinitrosalićlico) ${ }^{10}$.

A atividade proteolítica foi determinada pela técnica de azocaseína. A mistura de reação foi preparada com $1 \%(\mathrm{~m} / \mathrm{v})$ de azocaseína em tampão acetato $0,05 \mathrm{M}(\mathrm{pH} 5,5)$ como substrato. A reação enzimática foi climatizada para $30,40,50,55,60,65$ e $70^{\circ} \mathrm{C}$. Uma unidade proteolítica foi definida como o aumento de 0,01 na absorbância à $440 \mathrm{~nm}$ por minuto da reação teste, comparado com o controle da reação ${ }^{11}$.

Para análise do efeito da temperatura sobre a atividade amilolítica e proteolítica do extrato enzimático as reações foram realizadas em triplicata e os dados expressos em atividade relativa (\%).

\section{RESULTADOS E DISCUSSÃO}

A figura 1 mostra a atividade da amilase de $R$. oligosporus em uma faixa de 40 a $70{ }^{\circ} \mathrm{C}$. Foram verificados valores de atividade relativa superior a $85 \%$ nas reações climatizadas entre 55 e $65^{\circ} \mathrm{C}$. Houve uma redução para $64 \%$ a $70^{\circ} \mathrm{C}$, demonstrando que temperaturas mais elevadas ocasionam a desnaturação da enzima.

A protease de $R$. oligosporus apresentou atividade máxima à $55{ }^{\circ} \mathrm{C}$, de modo que observa-se valores superiores à $85 \%$ nos ensaios realizados entre 50 e $60^{\circ} \mathrm{C}$ (Figura 2). Estes dados demonstram um caráter termoestável da enzima estudada superior ao obtido pela protease purificada de Bacillus subtilis NRC 3, que apresentou temperatura ótima de $40{ }^{\circ} \mathrm{C}$, utilizando azocaseína como substrato ${ }^{12}$.

Figura 1. Efeito da temperatura sobre a atividade da amilase de Rhizopus oligosporus produzida por fermentação em estado sólido. 


\section{Anais do III Simpósio de Bioquímica e Biotecnologia Trabalho Completo apresentado na seção: PÔSTER}

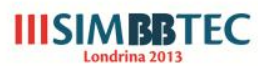

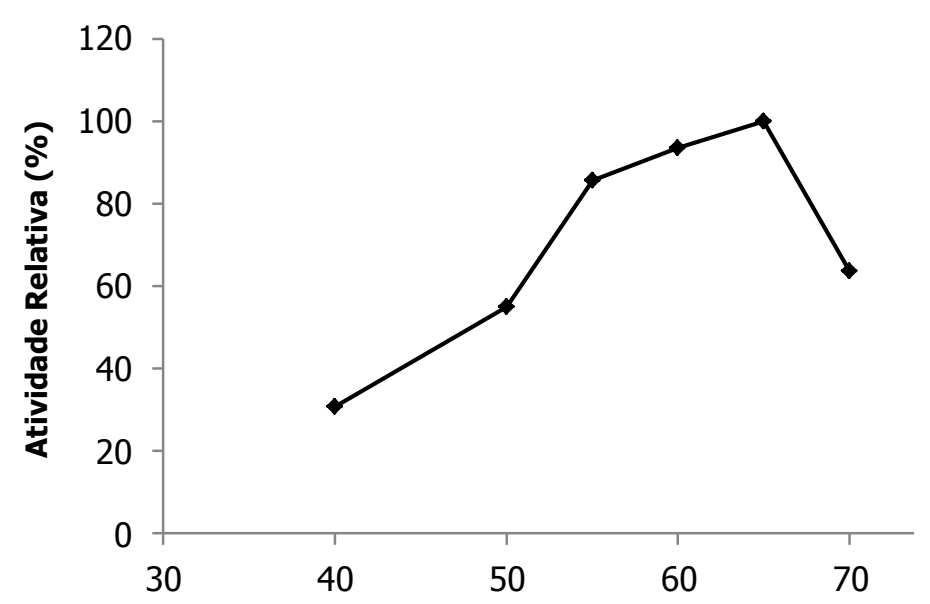

Figura 2. Efeito da temperatura sobre a atividade da protease de Rhizopus oligosporus produzida por fermentação em estado sólido.

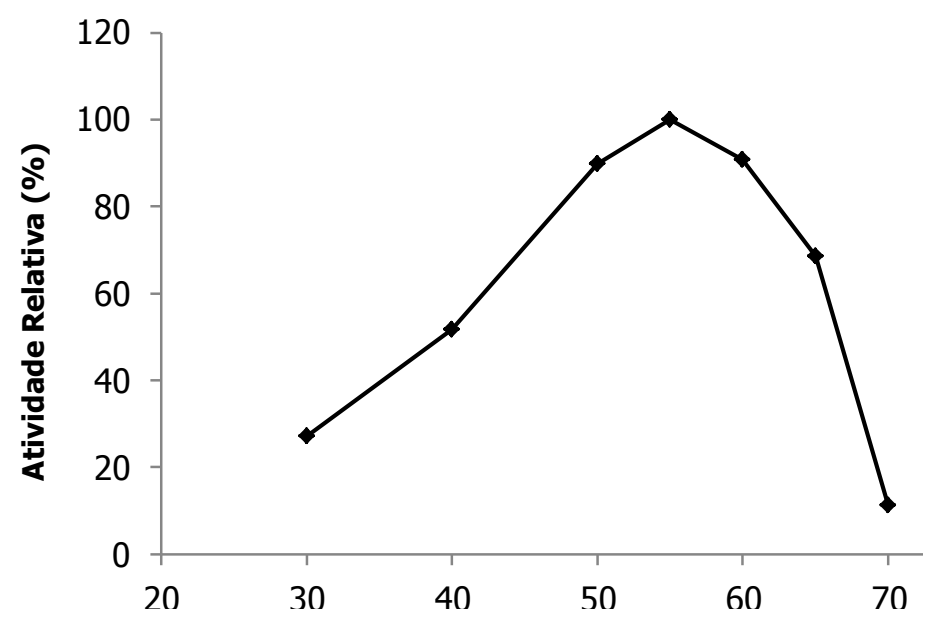

Diversos processos industriais empregam elevadas temperaturas, fazendo com que haja uma importante demanda por enzimas termoestáveis, como as produzidas por microorganismos termofilícos. No entanto, mesmo entre os mesófilos, como os fungos, que crescem entre $28^{\circ} \mathrm{C}$ e $32{ }^{\circ} \mathrm{C}$, é possível encontrar enzimas que atuam em temperaturas até $30^{\circ} \mathrm{C}$ acima da temperatura máxima de crescimento ${ }^{13}$.

Os dados revelam que ambas as enzimas produzidas pelo fungo apresentam uma faixa semelhante de temperatura para a obtenção dos maiores valores de atividade enzimática, o que permite que sejam aplicadas em conjunto nos processos que utilizam várias enzimas de forma concomitante.

\section{CONCLUSÕES}

As enzimas estudadas, produzidas por Rhizopus oligosporus em fermentação em estado sólido, apresentaram uma faixa de $10^{\circ} \mathrm{C}$ com atividade relativa acima de $85 \%$, sendo de 55 a 


\section{Anais do III Simpósio de Bioquímica e Biotecnologia Trabalho Completo apresentado na seção: PÔSTER}

$65^{\circ} \mathrm{C}$ para amilase e de 50 a $60{ }^{\circ} \mathrm{C}$ para protease. Esta característica indica versatilidade dos catalisadores, garantindo que sejam utilizados em múltiplos processos biotecnológicos que ocorrem em temperaturas elevadas.

\section{REFERÊNCIAS}

(1) KUMAR, V.; SAHAI, V.; BISARIA, V.S. Production of amylase and chlamydospores by Piriformospora indica, a root endophytic fungus. Biocatalysis and Agricultural Biotechnology, v. 1, p. 124-128, 2012.

(2) VAN DER MAAREL, M. J. E. C.; VAN DER VEEN, B.; UITDEHAAG, J. C. M.; LEEMHUIS, H.;

DIJKHUIZEN, L. Properties and applications of starch-converting enzymes of the a-amylase family.

Journal Biotechnology, v. 94, p. 137-155, 2002.

(3) MITIDIERI, S.; MARTINELLI, A. H. S.; SCHRANK, A.; VAINSTEIN, M. H. Enzymatic detergent

formulation containing amylase from Aspergillus niger. A comparative study with commercial detergent formulations. Bioresource Technology , v. 97, p. 1217-1224, 2006.

(4) CASTRO, A. M.; CARVALHO, D. F.; FREIRE, D. M. G.; CASTILHO , L. R. Economic analysis of the production of amylases and other hydrolases by Aspergillus awamori in solid-state fermentation of babassu cake. Enzyme Research, p. 1-9, 2010.

(5) LI, Q.; YI, L.; MAREK, P.; IVERSON, B. L. Commercial proteases: Present and future. FEBS Letters, v. 587, p. $1155-1163,2013$.

(6) GUPTA, R; GIGRAS, P.; MOHAPATRA, H; GOSWAMI, V. K.; CHAUHAN, B. Microbial a-amylases: a biotechnological perspective. Process Biochemistry, v.38, p. 1599-1616, 2003.

(7) SOUZA, P. M.; MAGALHÃES, P. O. Application of microbial a-amilase in industry - A review. Brasilian Journal of Microbiology, v. 41, p. $850-861,2010$.

(8) BARRIOS-GONZÁLEZ, J. Solid-state fermentation: Physiology of solid medium, its molecular basis and applications. Process Biochemistry. v. 47, p. 175-185, 2012.

(9) KEARSLEY, M. W.; DZIEDIC, S. Z. Handbook of starch hydrolysis products and their derivatives. London: Chapman \& Hall; 1995.

(10) MILLER, G. Use of dinitrosalicilic acid reagent for determination of reducing sugars. Analytical Chemistry. v.31, p. 426-428, 1959.

(11) LEIGHTON, T. J.; DOI, R. H.; WARREN, R. A. J.; KELLN, R. A.. "The relationshipof serine protease activity to RNA polymerase modification and sporulation in Bacillus subtilis". J. Mol. Biol., v.76, p.103122, 1973.

(12) TORK, S. E.; SHAHEIN, Y. E.; EL-HAKIM, A. E.; ABDEL-ATY, A. M.; ALYA, M. M. Production and characterization of thermostable metallo-keratinase from newly isolated Bacillus subtilis NRC 3 International Journal of Biological Macromolecules v. 55, p. 169- 175, 2013.

(13) GOMES, E.; GUEZ, M. A. U.; MARTIN, N.; SILVA, R. Enzimas termoestáveis: fontes, produção e aplicação industrial. Química nova, v. 30, n. 1, p. 136-145, 2007. 